\title{
Recorded Lower Esophageal Pressures as a Function of Electronic Sleeve Placement and Location of Gastric Pressure Measurement in Patients With Hiatal Hernia
}

\author{
Benjamin Basseri, ${ }^{1 *}$ Mark Pimentel, ${ }^{1}$ Christopher Chang, ${ }^{1}$ Edy E Soffer ${ }^{2}$ and Jeffrey L Conklin ${ }^{3}$ \\ ${ }^{1}$ GI Motility Program, Cedars-Sinai Medical Center, Los Angeles, CA, USA; ${ }^{2}$ Department of Medicine, Division of Gastroenterology, University \\ of Southern California, Los Angeles, CA, USA; and ${ }^{3}$ Center for Esophageal Diseases, University of California, Los Angeles (UCLA) Medical \\ Center, Los Angeles, CA, USA
}

\section{Background/Aims}

In high-resolution manometry lower esophageal sphincter pressure (LESP) is measured relative to intragastric pressure, however Gastric Marker $^{\mathrm{TM}}$ (GM) location used to determine resting LESP is not well established with hiatal hernia (HH). We test the hypothesis that measured resting LESP varies with $\mathrm{HH}$ based on GM location.

\section{Methods}

Subjects with $\mathrm{HH} \geq 2 \mathrm{~cm}$ were included. The eSleeve ${ }^{\mathrm{TM}}$ was adjusted to span only the LES, excluding the crural diaphragm (CD). Resting LESP was determined by placing the GM below and above the CD (in the position yielding the highest resting LESP). Resting pressure across the lower esophageal sphincter (LES) to CD and pressure in the HH relative to subdiaphragmatic intragastric pressure were also measured.

\section{Results}

$\mathrm{HH} \geq 2 \mathrm{~cm}$ was present in 98 patients (mean length $2.7 \mathrm{~cm}$ ). LESP decreased when GM was moved from below the CD into the $\mathrm{HH}$ : respiratory minimum LESP $7.5 \pm 1.1$ to $3.6 \pm 0.9 \mathrm{mmHg} ; P<0.001$, mean LESP $17.7 \pm 1.3$ to $13.7 \pm 1.1 \mathrm{mmHg}$; $P<0.001$. When the eSleeve encompassed the LES and CD, the respiratory minimum pressure was $12.2 \pm 0.9 \mathrm{mmHg}$ and mean pressure was $23.9 \pm 1.0 \mathrm{mmHg}$ pressure $(P<0.001$ for both). Pressure in the hernia pouch was greater than intragastric pressure: respiratory minimum $3.0 \pm 0.7 \mathrm{mmHg}$ and mean $9.0 \pm 0.8 \mathrm{mmHg}(P<0.001$ for both). pH studies showed a trend toward an association between abnormal distal esophagus acid exposure and lower resting LESP.

\section{Conclusions}

GM placement in the $\mathrm{HH}$ produces lower resting LESPs. This may provide a more physiologic representation of LESP in HH. (J Neurogastroenterol Motil 2013;19:479-484)

Key Words

Catheters; Esophagus; Gastroesophageal reflux; Hernia, hiatal; Manometry

Received: June 8, 2013 Revised: August 13, 2013 Accepted: August 27, 2013

(c) This is an Open Access article distributed under the terms of the Creative Commons Attribution Non-Commercial License (http://creativecommons. org/licenses/by-nc/3.0) which permits unrestricted non-commercial use, distribution, and reproduction in any medium, provided the original work is properly cited.

*Correspondence: Benjamin Basseri, MD GI Motility Program, Cedars-Sinai Medical Center, 8631 W 3rd St Suite 1015E, Los Angeles, CA 90048, USA

Financial support: None.

Tel: +1-310-652-4472, Fax: +1-310-358-2266, E-mail: basseri11@gmail.com

Conflicts of interest: None.

Author contributions: Benjamin Basseri: study design, data collection, data analysis, writing and revision of manuscript. Mark Pimentel: study design, data analysis, writing and revision of paper. Christopher Chang: study design and revision of paper. Edy E Soffer: study design and revision of paper. Jeffrey L Conklin: study design, data analysis, writing and revision of paper. 


\section{Introduction}

Esophageal manometry is used in the evaluation of gastroesophageal reflux disease (GERD) to localize the lower esophageal sphincter (LES) for $\mathrm{pH}$ probe placement, and to evaluate of esophageal motor function prior to anti-reflux procedures. ${ }^{1}$ The diagnostic capability of manometry has been greatly enhanced by the use of high-resolution manometry (HRM). ${ }^{2,3}$ HRM catheters consist of numerous closely spaced pressure sensors that allow simultaneous recording of pressure from the pharynx to the stomach. Advanced software programs transform the pressure data into topographical plots that give a detailed spatial and temporal representation of esophageal motor. Standard values are provided in the literature to aid the analysis process. ${ }^{2}$

Although there have been significant advances in the technical aspects of esophageal manometry, it is still an evolving tool with some associated limitations. One possible limitation is the accurate determination of resting lower esophageal sphincter pressure (LESP) in the setting of a hiatal hernia ( $\mathrm{HH})$. The convention is to measure resting LESP relative to intragastric pressure. However, from where in the stomach gastric pressure should be measured is not well defined in the literature and might be confusing. This is particularly true when a $\mathrm{HH}$ is present: should resting LESP be measured in the $\mathrm{HH}$ pouch or below the crural diaphragm (CD)? With modern HRM systems, positioning a tool called the Gastric Marker ${ }^{\mathrm{TM}}$ (Sierra Scientific Instruments, Culver City, CA, USA) can be used to choose the intragastric sensor used to calculate resting LESP. Therefore, resting LESP can be determined relative to gastric pressure in the $\mathrm{HH}$ pouch or in the stomach below the CD. We long thought that the measured value for resting LESP might depend upon in which of these locations the Gastric Marker is positioned. If this is so, quantifying resting LESP relative to intragastric pressure below the $\mathrm{CD}$ might not give a clear picture of LES function in the presence of a $\mathrm{HH}$. The accuracy of these measurements is paramount as these values help determine the choice of therapy in patients with impairment of esophageal motor function, such as GERD.

In this study, we compare resting LESPs determined as a function of intragastric pressure measured in the $\mathrm{HH}$ or below the $\mathrm{CD}$. We also aim to correlate intraesophageal $\mathrm{pH}$ exposure with these values.

\section{Materials and Methods}

\section{Subjects}

Consecutive patients presenting to a tertiary care medical center for HRM were eligible for inclusion in the study. Manometry studies demonstrating hiatal hernia $\geq 2 \mathrm{~cm}$ (measured manually from distal border of LES to proximal border of the $\mathrm{CD})$ were included in the study. Subjects without $\mathrm{HH}$ or with $\mathrm{HH}<2 \mathrm{~cm}$ were excluded from the study. Available data from esophageal $\mathrm{pH}$ testing were recorded. The Institutional Review Board approved this study.

\section{High-resolution Manometry}

Manometric recordings of esophageal motor function were acquired with the Manoscan ${ }^{\mathrm{TM}}$ manometry system (Sierra Scientific Instruments, Culver City, CA, USA). All subjects presented to the GI Motility Laboratory for HRM after a minimum 8-hour fast. Medications known to affect esophageal motor function were discontinued 5 days prior to HRM. A solid-state manometry catheter with 36 circumferential pressure transducers spaced at 1-cm intervals on center was used for the manometry (Sierra Scientific Instruments). A Manoshield ${ }^{\mathrm{TM}}$ (Sierra Scientific Instruments) was threaded over the catheter for sanitary protection. The catheter was calibrated from 0 to $300 \mathrm{mmHg}$ using externally applied pressure immediately prior to use. It was then inserted transnasally into the esophagus with distal channels located in the stomach as identified by positive pressure deflection with deep inspiration. The catheter was then positioned to incorporate visualization of the upper esophageal sphincter (UES) and LES in the field of view. This allowed simultaneous recording of pressure from the hypopharynx to the proximal stomach.

Patients were placed in a $15^{\circ}$ semi-recumbent position and allowed to accommodate to the catheter. Once comfortable, a 30 second recording was made with the patient at rest and not swallowing. This interval was delineated as the Landmark Frame $^{\mathrm{TM}}$ (Sierra Scientific Instruments). It was during this Landmark Frame that resting LESP was determined. Following this recording of pressures at rest, the subjects were given $5-\mathrm{mL}$, room temperature water swallows in a sequence of 10 swallows. Water swallows were given 30 seconds apart. Double swallows and swallows including pressure artifacts associated with coughing or belching were not counted in the 10 swallows. 


\section{Data Analysis}

Manometric recordings of esophageal motor function were evaluated with the Manoview ${ }^{\mathrm{TM}}$ software (Sierra Scientific Instruments). Resting pressures were assessed within the $30 \mathrm{sec}-$ onds Landmark Frame during which the patients did not swallow. A software algorithm resident in the Manoview software package called the electronic sleeve or eSleeve ${ }^{\mathrm{TM}}$ (Sierra Scientific Instruments) uses HRM pressure data to mimic a Dent sleeve. The default length of the eSleeve is $6 \mathrm{~cm}$, but it can be adjusted to encompass varying numbers of contiguous pressure sensors. During the Landmark Frame, the Manoview software calculates respiratory minimum and mean LESPs relative to intragastric pressure. Manual positioning of a tool call the Gastric Marker $^{\mathrm{TM}}$ (Sierra Scientific Instruments) allows us to choose the intragastric sensor used to calculate resting LESP.

The eSleeve was first adjusted and positioned to span just the LES, excluding the CD. The esophagogastric junction (EGJ) in normal anatomy is a composite of tonic LES contraction and cylindrical CD contraction with inspiration. Because an inclusion criteria of the study is the presence of $\mathrm{HH}$ of $2 \mathrm{~cm}$ or more, the $\mathrm{CD}$ component is not included in this measurement. Therefore, LES pressure measurement in this study is defined as the pressure provided by tonic LES contraction alone and should be the same as EGJ pressure. Respiratory minimum and mean LESPs were determined relative to pressure in the $\mathrm{HH}$ pouch or in the stomach below the CD. This was done by placing the Gastric Marker above the $\mathrm{CD}$ or within the $\mathrm{HH}$. The location of the Gastric Marker was standardized by choosing the position which yielded the highest resting LESP within each of these zones (Fig.

Table. Pressure Profiles in Different Measurement Zones

\begin{tabular}{lcccc}
\hline & & \multicolumn{3}{c}{ Pressure profiles } \\
\cline { 2 - 4 } & Minimum $(\mathrm{mmHg})$ & $P$-value & Mean $(\mathrm{mmHg})$ & $P$-value \\
\hline Resting LESP when GM is located in the stomach & $7.5 \pm 1.1$ & - & $17.7 \pm 1.3$ & - \\
Resting LESP when GM is located in the hernia sac & $3.6 \pm 0.9$ & $<0.001$ & $13.7 \pm 1.1$ & $<0.001$ \\
Resting pressure of high pressure zone & $12.2 \pm 0.9$ & - & $23.9 \pm 1.0$ & - \\
Resting pressure in hernia sac & $3.0 \pm 0.7$ & - & $9.0 \pm 0.8$ & - \\
\hline
\end{tabular}

In reference to lower esophageal sphincter pressure (LESP) with intragastric pressure (IGP) landmark below the crural diaphragm (CD), LESP with IGP landmark above the $\mathrm{CD}$ and pressure within the hernia sac were significantly lower while the minimum and mean pressures in the pressure zone spanning from the proximal LES to distal CD were significantly higher.

Values are presented as mean $\pm \mathrm{SE}$.
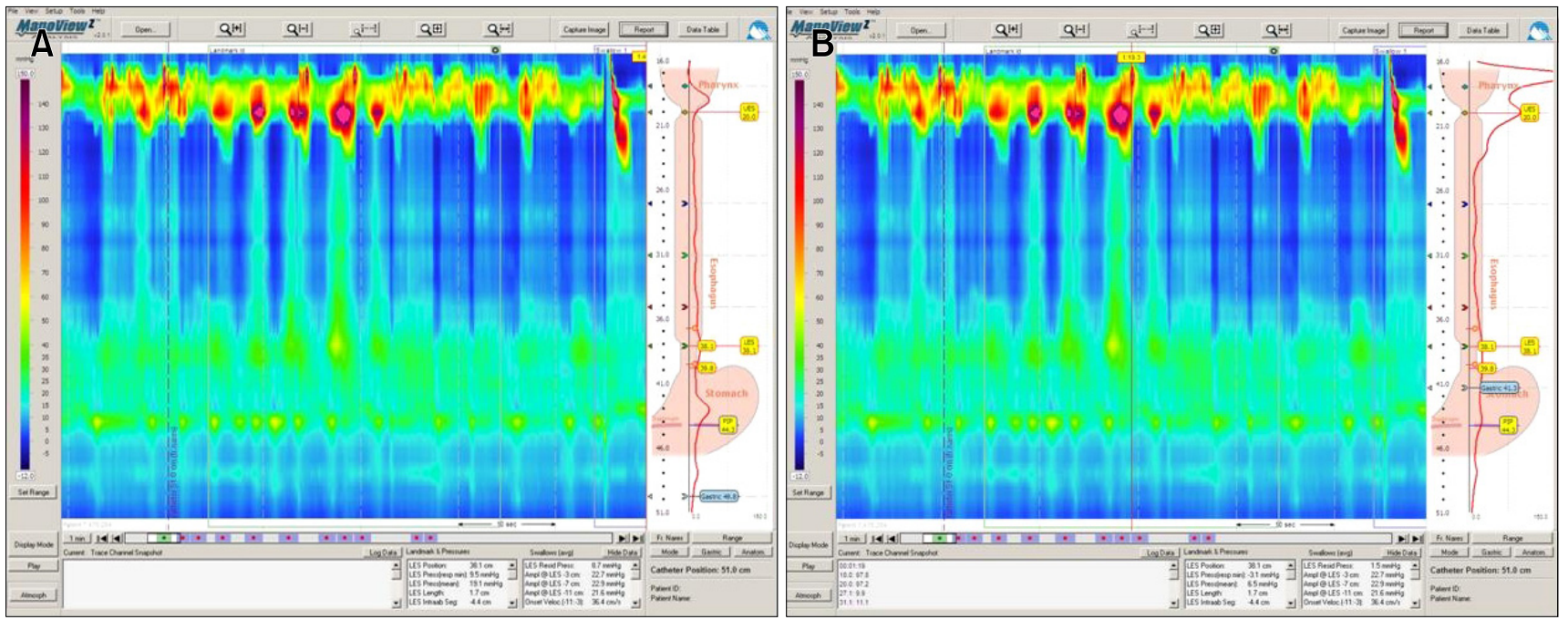

Figure 1. Gastric Marker placement below (A) and above (B) the crural diaphragm in hiatal hernia. The Gastric Marker placement is denoted by the blue marker on the right side of the image. Note that the zone within the hernia in this case is greener, denoting higher pressure. 
1). For instance, the location of the Gastric Marker for traditional measurement of the LESP and measurement of the high pressure zone spanning from the CD to the LES was chosen based on the position within the non-hernia stomach which provided the highest value measurement within these pressure zones. For measurement within the hernia sac, the Gastric Marker was positioned at the location within this zone which provided the highest LESP. The eSleeve was then adjusted to span from the proximal boundary of the LES to the distal boundary of the CD in order to provide an assessment of resting pressure across the entire high-pressure zone (LES, HH and CD). Finally, the eSleeve was adjusted from the distal boundary of LES to proximal boundary of $\mathrm{CD}$ so that resting pressure in the $\mathrm{HH}$ pouch could be measured.

\section{pH Studies}

The electronic medical records of all subjects included in the study were reviewed for data from 24 or 48 -hour $\mathrm{pH}$ studies. Time $\mathrm{pH}<4$ in the proximal and lower esophagus were recorded. Abnormal acid exposure was defined as time with $\mathrm{pH}$ $<4$ greater $5 \%$ or $1 \%$ of the study duration in the distal or proximal esophagus, respectively. The number of reflux episodes in the distal and proximal esophagus, respectively, was also recorded.

\section{Statistical Methods}

Comparisons of continuous data were made by paired t test using appropriate statistical software. A $P$-value of $<0.05$ was considered significant. Continuous data were expressed as a mean \pm standard error of mean (SEM). Regression statistics using a linear analysis were utilized to assess relationships with percent total acid exposure in the distal esophagus.

\section{Results}

\section{Subjects}

HRM studies of 98 consecutive subjects with hiatal hernia $\geq 2 \mathrm{~cm}$ were analyzed. Mean hiatal hernia length was $2.7 \pm 0.1$ $\mathrm{cm}$.

\section{Pressure Profiles}

Respiratory minimum LESP was $7.5 \pm 1.1 \mathrm{mmHg}$ when the Gastric Marker was positioned below the $\mathrm{CD}$, and $3.6 \pm 0.9$ $\mathrm{mmHg}$ when placed in the $\mathrm{HH}(P<0.001)$ (Table and Fig. 2).

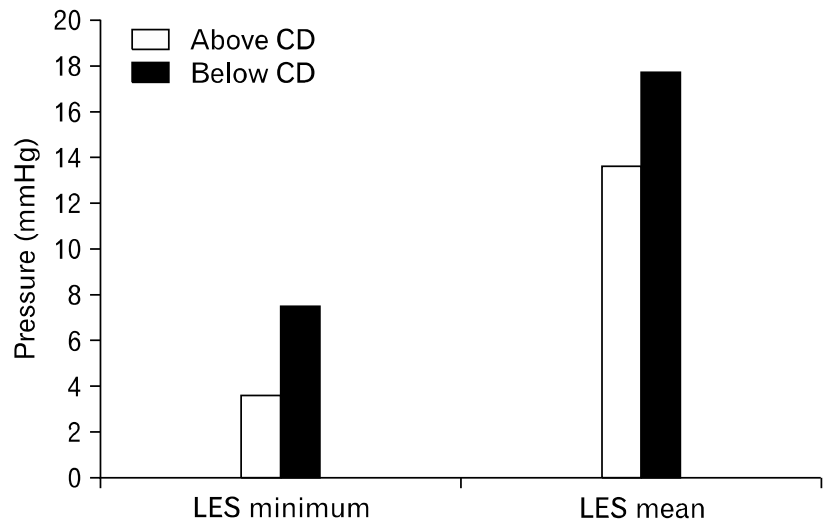

Figure 2. Comparison of placement of Gastric Marker above and below crural diaphragm (CD) in hiatal hernia. Lower esophageal sphincter (LES) minimum and mean pressure were both significantly lower $(P<0.001)$ with placement of the Gastric Marker above than below the $\mathrm{CD}$.

Mean resting LESP was $17.7 \pm 1.3 \mathrm{mmHg}$ with the Gastric Marker below the $\mathrm{CD}$, and dropped to13.7 $\pm 1.1 \mathrm{mmHg}$ when it was moved into the $\mathrm{HH}$ pouch $(P<0.001)$. When the eSleeve was adjusted to span the LES, HH and CD and the Gastric Marker was positioned below the CD, respiratory minimum pressure rose to $12.2 \pm 0.9 \mathrm{mmHg}$, and mean resting pressure to $23.9 \pm 1.0 \mathrm{mmHg}$. Relative to intragastric pressure below the $\mathrm{CD}$, respiratory minimum pressure within the $\mathrm{HH}$ was $3.0 \pm 0.7 \mathrm{mmHg}$ and mean pressure was $9.0 \pm 0.8 \mathrm{mmHg}$ : both lower than resting LESPs, but higher than subdiaphragmatic intragastric pressure (Table).

\section{Distal Esophageal Acid Exposure}

We evaluated data from 24-hour ambulatory intraesophageal $\mathrm{pH}$ studies in those subjects $(\mathrm{n}=36)$ who had this study performed at our medical center. Those subjects with abnormal distal esophagus acid exposure had lower minimum (3.1 \pm 2.4 vs. $8.1 \pm 2.7 \mathrm{mmHg}, P=0.085)$ and mean $(12.8 \pm 3.1$ vs. $19.3 \pm$ $3.2 \mathrm{mmHg}, P=0.084)$ LESP with Gastric Marker below the CD. With Gastric Marker above CD, subjects with increased acid exposure also had lower measured minimum (-0.1 \pm 2.5 vs. $2.5 \pm 1.7 \mathrm{mmHg}, P=0.242)$ and mean $(9.7 \pm 2.6$ vs. $13.6 \pm$ $2.3 \mathrm{mmHg}, P=0.135)$ LESP, although these differences did not reach statistical significance. Linear regression analysis did not reveal a statistically significant association between increased acid exposure (percent time $\mathrm{pH}$ was below 4 in the distal esophagus) and any of the pressure zones evaluated (Gastric Marker below CD, Gastric Marker above CD, pressure zone across LES 
to $\mathrm{CD}$, or pressure zone within $\mathrm{HH}$ ). In other words, neither placement of Gastric Marker below or above the CD provided LES pressures which correlated well with increased distal esophagus acid exposure.

\section{Discussion}

We evaluated how positioning the Gastric Marker and eSleeve during the analysis of HRM of 98 subjects with $\mathrm{HH}$ might alter reported values for resting LESP. Respiratory minimum and mean LESP reported by Manoview algorithms varied significantly as a function of where and how these tools were positioned. When the Gastric Marker was moved from its subdiaphragmatic position into the $\mathrm{HH}$, reported respiratory minimum and mean pressures dropped significantly. This indicates that in our patients resting pressures in the $\mathrm{HH}$ are greater than in the subdiaphragmatic stomach (Fig. 1). Here, the green hue within the $\mathrm{HH}$, represents higher pressure than the more blue color below the $\mathrm{CD}$. This is supported by our observation that pressure measured in the $\mathrm{HH}$ by the eSleeve is greater than subdiaphragmatic intragastric pressure. While we did not directly address this question, this observation suggests that the pressure gradient across the LES may be greater with a $\mathrm{HH}$ than when the stomach is normally positioned below the $\mathrm{CD}$. In the presence of a $\mathrm{HH}$, calculating resting $\mathrm{LES}$ pressures relative to $\mathrm{HH}$ pressure might be more physiologically relevant than calculating them relative to subdiaphragmatic intragastric pressure. This is because the gastric pressure adjacent to the LES is that within the $\mathrm{HH}$.

Sparse data are available regarding assessment of $\mathrm{HH}$ with HRM. ${ }^{1,4-7}$ Crural CD function is an independent predictor of GERD and LES-CD separation is associated with GERD. ${ }^{5}$ The presence of $\mathrm{HH}$ may be a pivotal contributor to compromised LES function. ${ }^{6}$ In our regression analysis of 36 subjects with available $\mathrm{pH}$ studies, there was a trend between increased distal esophagus acid exposure and lower resting LESPs with Gastric Marker placed either below or above the CD, but these differences did not reach statistical significance in either case.

A previous report suggests that $\mathrm{CD}$ function may augment the barrier at the EGJ and the loss of this function is reflected by this increase in acid exposure in the distal esophagus. ${ }^{5} \mathrm{HH}$ has been showed to alter dynamic responsiveness of LESP by spatially separating pressure components of the LES and extrinsic esophageal compression within the hernia canal ${ }^{8}$ and shape of the EGJ has been shown to correlate with grade of esophagitis. ${ }^{9}$ The severity of $\mathrm{HH}$ may also influence susceptibility to reflux. In a HRM comparison of type I (separation but still some overlap between LES and CD) and type II (LES and CD completely separated) $\mathrm{HH}$, reflux events were twice as likely to occur with the latter EGJ spatial configuration. ${ }^{10}$ These data are corroborated by the increase in minimum and mean pressure we appreciated with the eSleeve spanning from the LES to the CD $(12.2 \pm 0.9$ $\mathrm{mmHg}$ ) compared to traditional measurement including the boundaries of the LES only $(7.5 \pm 1.1, P<0.001)$.

Furthermore, the CD may play a role in the etiology of dysphagia in patients with $\mathrm{HH}$. Subjects with $\mathrm{HH}$ and dysphagia have higher residual CD pressure and intrabolus pressure compared to subjects with $\mathrm{HH}$ and GERD. ${ }^{11}$ This suggests that $\mathrm{HH}$ alters pressure dynamics at the EGJ and may lead to functional obstruction. It is conceivable that not only the $\mathrm{CD}$ but the high pressure zone created between the LES and CD in patients with $\mathrm{HH}$ may create functional obstruction and dysphagia.

In summary, we demonstrated lower minimum and mean LESP in subjects with $\mathrm{HH}(\geq 2 \mathrm{~cm})$ with Gastric Marker measured within the $\mathrm{HH}$ compared to traditional measurement below the CD. This difference may be explained by the demonstration of higher pressure within the hernia sac compared to the zone below the $\mathrm{CD}$. This novel measurement technique may provide a more physiologic representation of the pressure profile across the LES in patients with $\mathrm{HH}$ and further investigation is necessary to validate this measurement.

\section{References}

1. Pandolfino JE, Kahrilas PJ, American Gastroenterological Association. AGA technical review on the clinical use of esophageal manometry. Gastroenterology 2005;128:209-224.

2. Fox M, Hebbard G, Janiak P, et al. High-resolution manometry predicts the success of oesophageal bolus transport and identifies clinically important abnormalities not detected by conventional manometry. Neurogastroenterol Motil 2004;16:533-542.

3. Conklin JL. Evaluation of esophageal motor function with high-resolution manometry. J NeurogastroenterolMotil 2013;19:281-294.

4. Bredenoord AJ, Weusten BL, Carmagnola S, Smout AJ. Doublepeaked high-pressure zone at the esophagogastric junction in controls and in patients with a hiatal hernia: a study using high-resolution manometry. Dig Dis Sci 2004;49:1128-1135.

5. Pandolfino JE, Kim H, Ghosh SK, Clarke JO, Zhang Q, Kahrilas PJ. High-resolution manometry of the EGJ: an analysis of crural CD function in GERD. Am J Gastroenterol 2007;102:1056-1063.

6. Kahrilas PJ, Peters JH. Evaluation of the esophagogastric junction using high resolution manometry and esophageal pressure topography. Neurogastroenterol Motil 2012;24(suppl 1):11-19.

7. Kahrilas PJ, Clouse RE, Hogan WJ. American Gastroenterological 
Association technical review on the clinical use of esophageal manometry. Gastroenterology 1994;107:1865-1884.

8. Kahrilas PJ, Lin S, Chen J, Manka M. The effect of hiatus hernia on gastro-oesophageal junction pressure. Gut 1999;44:476-482.

9. Kang CD, Song CW, Koo JK, et al. Relationship between the shape of the gastroesophageal junction and gastroesophageal acid reflux. Korean J Gastrointest Motil 2001;7:29-35.
10. Bredenoord AJ, Weusten BLAM, Timmer R, Smout AJ. Intermittent spatial separation of diaphragm and lower esophageal sphincter favors acidic and weakly acidic reflux. Gastroenterology 2006;13: 334-340.

11. Pandolfino JE, Kwiatek MA, Ho K, Scherer JR, Kahrilas PJ. Unique features of esophagogastric junction pressure topography in hiatus hernia patients with dysphagia. Surgery 2010;147:57-64. 